\title{
Where Virtual Enhances Physical Mock-Up: A Way to Understand our Heritage
}

\author{
Florent Laroche ${ }^{*}$ \\ IRCCYN, LUNAM \\ Université, École \\ Centrale Nantes, Nantes
}

\author{
Myriam Servièrest \\ CERMA , LUNAM \\ Université, École \\ Centrale Nantes, Nantes
}

\author{
Daniel Lefèvre ${ }^{\ddagger}$ \\ Engineering student, \\ École Centrale Nantes, \\ Nantes
}

\section{Jean-Louis \\ Centre François Viète, Université de Nantes, Nantes}

\begin{abstract}
In Museum, many testimonies of our cultural heritage can be found. But because of their high fragility, the public can not get too close to them. In this communication we will explain a project that deals with a physical mock-up of Nantes harbor; the mock-up has been built in 1899 and shown in 1900 for the World's Fair that took place in Paris, France. This heritage object is nowadays at the "Château des Ducs" museum in Nantes, France, but shown behind panes. The object has been digitized and a 3D model has been reconstructed. Thanks to a virtual system coupled to a touchscreen with semantic research modules and to a light pointer, it will allow the visitor to better understand the mock-up and the associated history. Moreover, the system will be user-centered: the visitor will interact directly with the digital mock-up and obviously with all the knowledge that allows the contextualization.
\end{abstract}

KeYwoRDS: Cultural Heritage, Interaction and Interactivity, Museums, Industrial Archaeology.

INDEX TERMS: H.1.0 [Models and principles]: General; H.2.m [Database management]: Miscellaneous; H.3.4 [Information storage and retrieval] Systems and Software - Question-answering (fact retrieval) systems**; H.5.1 [Information interfaces and presentation (i.7)] Multimedia Information Systems -Artificial, augmented, and virtual realities, Hypertext navigation and maps**

\section{INTRODUCTION}

In museum, many objects of our cultural heritage are too fragile to be shown to the public, except behind windowpanes, which prevent people to get too close. Of course, this caution avoids objects to be damaged, but the public can't get close enough to be immersed or to interact with the physical object. The mock-up of Nantes harbor in 1900 is one of those museum objects.

This mock-up is both a description of Nantes history and an

\footnotetext{
$*, \dagger, \ddagger$ École Centrale Nantes, 1 rue de la Noë, 44321 Nantes

* florent.laroche@irccyn.ec-nantes.fr

† myriam.servieres@ec-nantes.fr

\$daniel.lefevre@eleves.ec-nantes.fr

$\S$ Centre François Viète, 2 rue de la Houssinière, 44000 Nantes, jean-louis.kerouanton@univ-nantes.fr
}

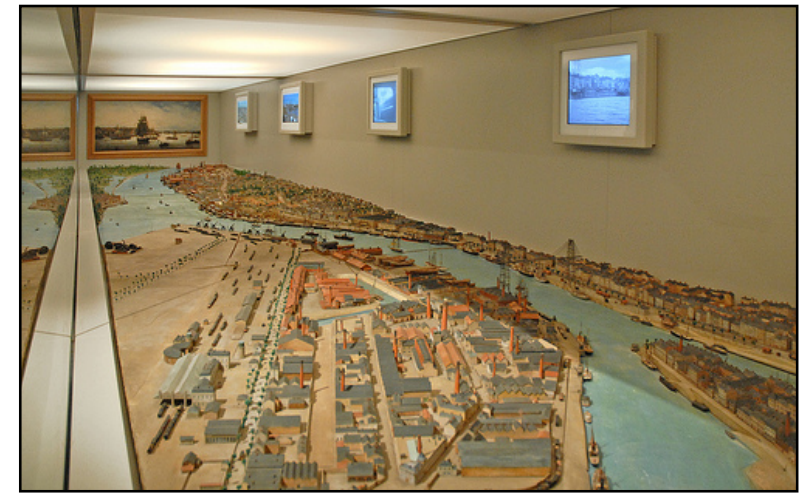

Figure 1. The physical mock-up behind windowpanes

historical object. Indeed, it was a command of the Chamber of Commerce and Industry for the 1900 Word's Fair. Designed by Paul Duchesne in 1898, it has undergone constant changes until 1913, becoming a testimony of Nantes' evolutions. Presented in Room 21 of the Nantes History Museum located in the "Chateau des Ducs de Bretagne", it is a relief map of 9.20 meters long and 1.85 meters wide, covering about sixty acres of the industrial harbor of Nantes, from the city center to west districts (figure 1). The model scale is approximately $1 / 500$. It is made with wood, metal finishes, plant materials, paper and glass, and despite a restoration in 1996-1997, it remains relatively fragile [1]. Currently, this mock-up is simply exposed to the public in a display case, behind it there are videos showing pictures of Nantes harbor at different periods (1920, 1949 and 2005). This presentation is unattractive and poorly adapted to the quality of the object.

Digital acquisition will allow an historical analysis of Nantes industrial harbor that took an important role in the early twentieth century. It is not only a $3 \mathrm{D}$ model because we would pretend to merge this topographic map and documentary data that will help to understand links between major units of the industrial landscape, shipping and commercial networks of Nantes city. Consequently, this project aims to create a knowledge database that will be used at the same time by researchers and by curious public. The mock-up study highlights the relationship between the harbor, the city and the river; from an architectural point of view, it allows merging the landscape and the town development structure.

This project is in the field of museography for enhancing our heritage using new technologies. A multitouch interface will be available for allowing a visitor to use the interactive model. Thanks to a very large diagonal screen, the visitor will be able to choose by himself the place he wants to learn more. He will select 
an area on the 3D digital reproduction of the city and the system will return him the knowledge database graphically (figure 6).

A visualization system based on popup allows dynamic areas illuminations and multiple users manipulations. A lighting system will point the same place but directly on the physical mock-up, offering the user the possibility to identify the object in the "real life"(figure 2).

Next in this paper, section 2 presents a state of the art of other projects in the same area. In section 3 we present the archaeological project description that consists in our scientific methodology. In section 4 we detail some part of the "Nantes 1900 project" experiment.

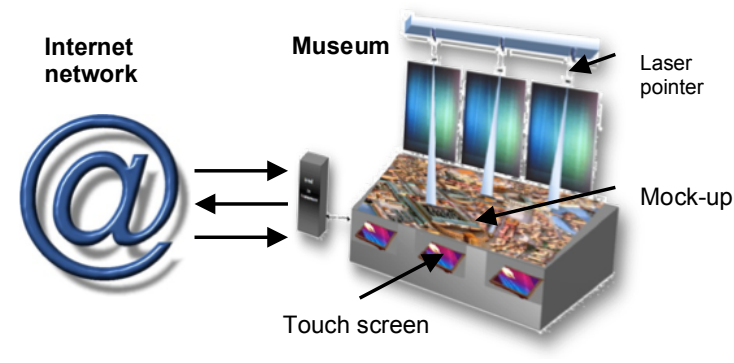

Figure 2. Diagram of the future vulgarization system

\section{STATE OF THE ART}

If we consider the digitization project of Nantes 1900 mock-up as a simple virtual reality system, we can found various other projects in the same field. However, we must notice that our project will go further as a knowledge database is added to it.

Nantes museum is one of the most famous museums in France containing many interactive applications dedicated to visitors. For example, one of them helps to discover the city of Nantes in 1757. The open source software proposes to navigate into a virtual world thanks to Ogre 3D. However, those kinds of projects are not similar to Nantes 1900 project as they propose a virtual model reconstructed thanks to historical maps or writings and not directly from a 3D physical mock-up; moreover there is no interaction between the "virtual world" and the "real life".

Few projects propose to digitize a large heritage object and to create a virtual model with many levels of details that are chosen by the users [2-6]. Last experimentation known is the 3D digitalization of a physical mock-up of the city of Prague designed by Langweil. Data have been acquired by photographic systems [2]. Another experiment has been done by the "Musée des Maquettes" in France [3]. The physical mock-up representing the city of Toul has been digitalized in 3D and many photos have been taken. Then, the clouds of points have been combined in order to obtain a parametric virtual model. We can also quote the project named Rome Reborn whose purpose is to rebuild the city of Rome between the years $1000 \mathrm{BC}$ to $500 \mathrm{AD}$. This project required numerous plans but also historical documents to understand the physical mock-up [4-6].

Every kind of digitization raised numerous problems. One of the most important of them is that it is impossible to visualize the enormous quantity of points acquired: files are so heavy. There are no software that can manipulate easily 200 millions of points. Consequently, digitized data were divided into several areas for being viewed independently and then simplified. We can find similar projects with art works digitization problem as The Digital Michelangelo Project [7].

The main idea developed in this communication is the use of virtual technologies for cultural heritage enhancement. But, when we talk about heritage, there is not only architecture or castles as the architect Houdin and Dassault System have demonstrated using Catia V5 for understanding the Cheops pyramid [8]. Indeed, objects studied by our research teams belong to scientific and/or technical domains. Machines, industries and socio-economical context are also very important for a better understanding of our history. Our proposition consists in overturning the time axis of the design process generally used for developing contemporary technical products. Following the same method, one experience has been done by the museum of Florence about the virtual understanding for reconstructing one of Leonardo da Vinci automobile [9].

Contrary to examples presented in this state of the art, the specificity of all those projects is that the work is done manually; nothing is automatic [10-11]. Few algorithms are presented but they only state the process followed [12]. Concerning the Nantes 1900 project, it would be impossible to do it manually due to the amount of data: neither the 3D cloud of points, nor the historical documents.

\section{Project SCIENTIFIC DESCRIPTION}

From a methodological point of view, before defining the final museographic system, it is crucial to establish a knowledge database that can explain the object. It is what we call the Digital Heritage Reference Model (DHRM). Thanks to it, we can imagine and create numerous finalities for experts, scholars, internet, etc.

One important aspect of the project is that the DHRM that can encapsulate the knowledge: also the 3D virtual mock-up issue from the 3D cloud of points and the historical documents associated. Data can be heterogeneous: papers, photos, sounds, videos, etc. and the system would propose to do some semantic requests.

The aim of the digitization process is not to create an animation with a nice rendering. It will be a real representation of the physical world with all the characteristics and dynamical constraints it includes. In order to reach the final virtual model, CAD software (Computer Aided Design) and engineering simulation tools (coming from enterprises) must be used. The global process is called "Advanced Industrial Archaeology". The main goal of this new discipline is to successfully complete the combination of all virtual tools existing in order to capitalize and better understand our heritage.

This global process is the core of what we call Advanced Industrial Archaeology:

- First step is the digitization of the physical object and the capitalization of the know-how learnt by studying the machine or here in our case the physical mock-up.

- Next, thanks to virtual reality technologies, we can valorize this amount of knowledge.

Nowadays, the methodology to design an old technical object has been validated and experimented on several case studies by our research team: capitalize - formalize - develop. For this new project, and mainly for "Nantes 1900 project", the aim is to demonstrate that the methodology can also be used for capitalize for industrial plants [13]. 


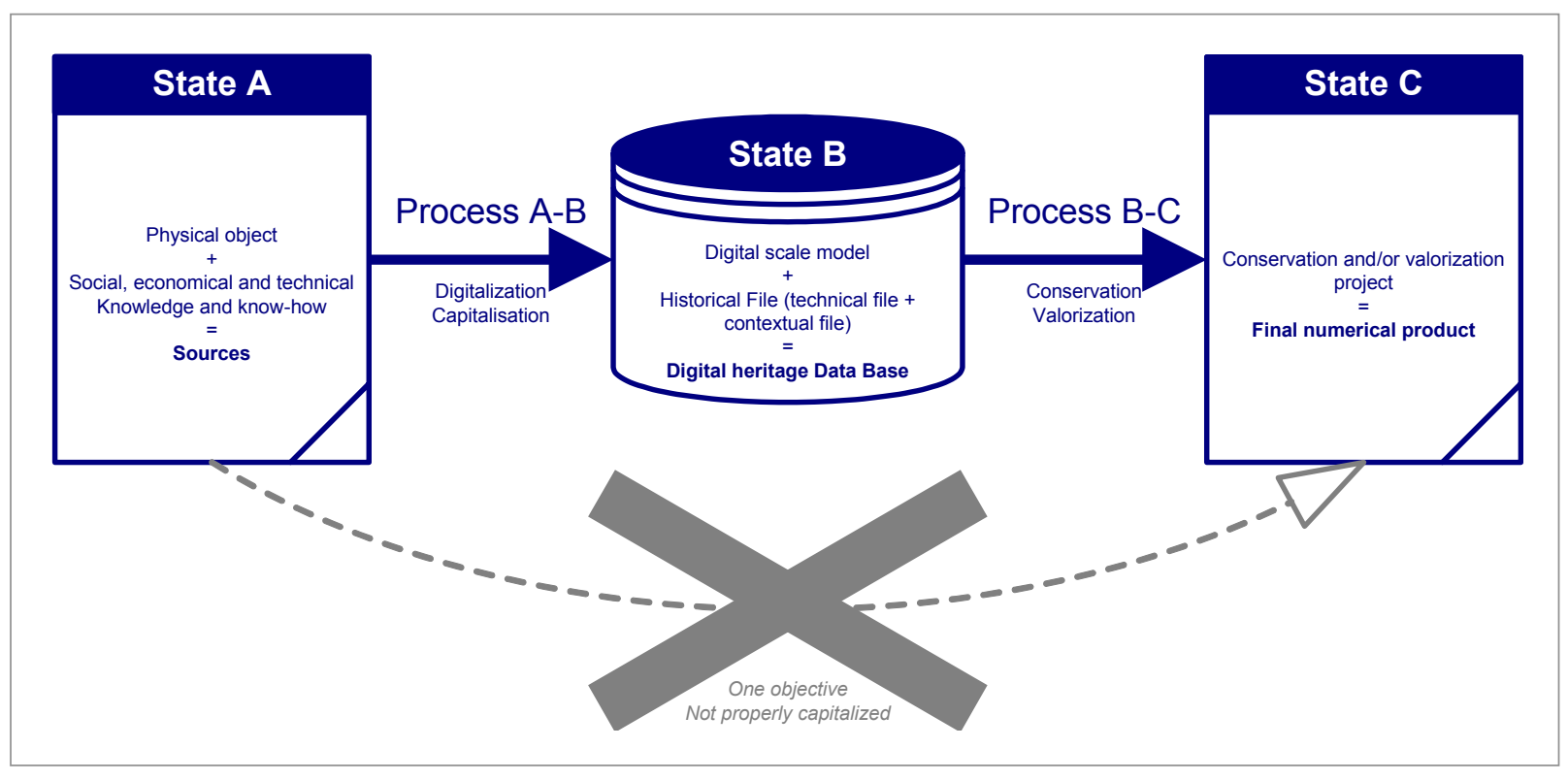

Figure 3. Scientific method for capitalizing, formalizing and developing our heritage

Advanced Industrial Archaeology proposes 3 main stages (figure 3). One advantage of introducing the state B is to have the possibility of numerous finalities. In fact, going directly from state A to state $\mathrm{C}$ is not recommended. The various possibilities of final numerical product of state $\mathrm{C}$ (virtual thesaurus use for teaching or academic experts, reconstruction, museum valorization...) show that it is necessary to capitalize a maximum amount of knowledge at the beginning of the heritage preservation project. Then, an intermediate structure containing all information, data and knowledge is required. It is a new virtual document that informs the heritage object. It is constituted of a virtual database allowing organizing the knowledge involved. It is what we call the Digital Heritage Reference Model (DHRM). Due to the complexity of the meta-model of the database, it is very complicated to create it.

\section{4 “NANTES1900 PROJECT" EXPERIMENT}

\subsection{Prerequisite and museographic constraints}

This project belongs to technical history and industrial engineering field; it also deals with 3D modeling and museographic development. The project was built as an open system that should progress. Its interest lies in its innovativeness, both in terms of the approach used and its limitations but also in the methods developed in this project where high technology serves history. This project is multidisciplinary. It requires skills from history and industrial heritage (university faculty of history and laboratory "Centre François Viète"). It also relies on the technical expertise from engineering sciences (Ecole Centrale Nantes and Ecole Polytechnique Nantes, in connexion with local laboratories).

From a museographic point of view, project specifications are very light: user interface has to be simple, attractive, intuitive, practical and robust. Every visitor should be able to use it (for example children or disabled persons). No specific device should be used, i.e. no HMD, no remote control, etc. The system should be multi users and even those who do not interact with the system should see the data. The system has to be internationalized and it could evolve from integrating new data in its semantic database. The whole computer part has to be open source.

\subsection{From the physical mock-up to cloud of points}

The mock-up was digitized using a scanner from the Company Creaform (www.creaform3d.com). Based on a Canadian patent, this tool allows digitizing an object to get a cloud of points. The scanner is self-positioned in 3D space thanks to reflecting targets. It is possible to scan many times the same point to optimize its position. This technique is without contact and cannot destroy the object. Moreover, we had the constraint that turning around or going above was very difficult because the mock-up must stay in the room and its dimensions are big. Consequently, as Handyscan is handled, it allows user to position it wherever he wants.

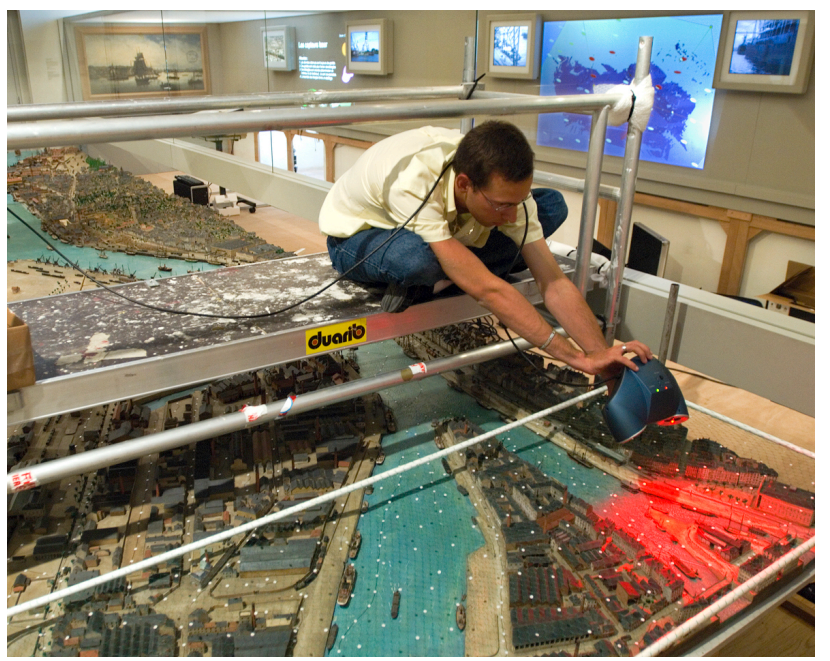

Figure 4. 3D digitization inside the museum 


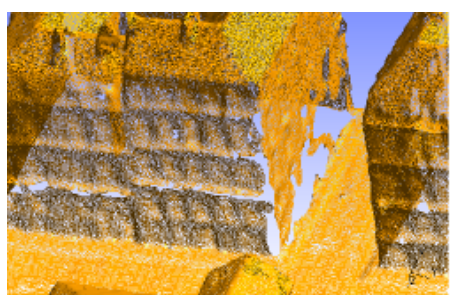

(a) Holed mesh

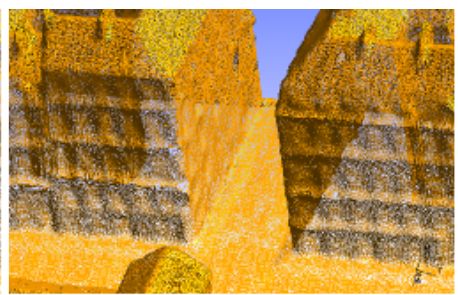

(b) Filled mesh

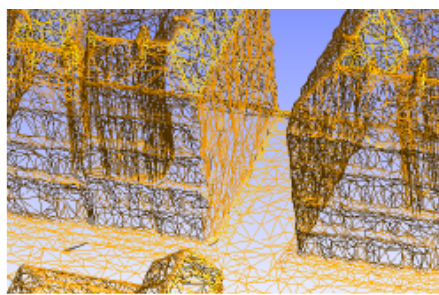

(c) Decimated to $10 \%$

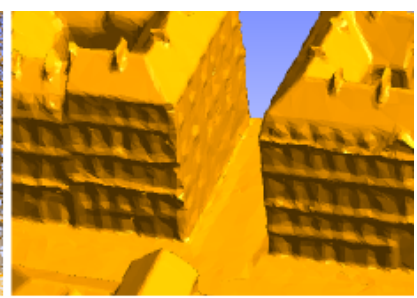

(d) Surface view

Figure 5. Point cloud to 3D model

Considering that the mock-up on a scale of 1:500 it means that a human measures approximately $3 \mathrm{~mm}$ inside the physical mock-up. Notice that the chosen precision for the $3 \mathrm{D}$ digitization is $0.53 \mathrm{~mm}$; that means the virtual model contains one point each $265 \mathrm{~mm}$. Mathematicians or geographical people specialized in GIS (Geographical Information System) say such resolution is incredible. Indeed, that means we obtain a 3D model at $26 \mathrm{~cm}$ precision but on the scale of a city!

\subsection{From cloud of points to 3D model}

There are several steps to go from cloud of points to 3D model. They are led to the conversion from a mesh to a semantic meaning mock-up, using algorithms to fill up the model with information like photos, maps and geographical coordinates.

Besides the 3D model, we aim at getting one 3D raster and one vectorized mock-up (2D, and $3 \mathrm{D}$ with semantic information, and the ability to contain more data). However, scanning induces a numerical error, which must be calculated.

First we get a huge cloud of points; but the acquisition is not perfect: there are some holes in the mesh (figure 5 (a)). Manually, the different files have to be verified and the holes have to be filled (figure 5 (b)). One important step for building a realistic mock-up consists in decimating the mesh: current technologies are not able to load easily 100,000,000 triangles. This implies to simplify the model and to use algorithms for correcting it but also keeping the topology of the buildings. We use OpenMesh and its quadric mode decimator to simplify the mesh on each yard (figure $5(\mathrm{c}))$.

Then we aim at vectorizing the $3 \mathrm{D}$ model. In order to do that, we spread the 3D vectorized mock-up on semantic part: we segment it. By segmentation, we mean separation between walls, roofs, and grounds. The segmentation phase is very important before applying the following algorithms. It is also important to begin adding semantic information as soon as possible into the model because this information will be spread through the database to the public and on the Internet.

Then, we have to texture the model. It will be the assembly of pictures with the semantic information given during the segmentation. This will output the coordinates of the textures as a additional semantic information and will be integrated directly in the 3D mock-up.

Vectorization is the last step of the construction of the mock-up: from all the segmented files, the mock-up has now to be converted into a $3 \mathrm{D}$ vectorized format, and each building must be described as vector forms, and not triangles anymore. The vectorized 2D image will be then calculated as the projection of the buildings on the floor (by deleting the $\mathrm{z}$ axis).

\subsection{From database to visitor/internet interaction}

Using new technologies, this project doesn't aim only at enhancing the physical mock-up but has also other uses. Indeed, such a project will never "end".

The study of current databases shows that they are almost all based on the same model (for exemple Merimee for French culture ministry). The Nantes1900 project database supports all possible information on the model (both documentary and digital) and has the advantage of being scalable and open source. It is not only to identify and make an inventory of objects in the relief map; it also serves for opening new perspectives for literature researches.

The database could evolve itself as well as it will be a complete traceability of the information it contains. We will explain it later in this article.

Moreover, this database is linked with the touchpad (figure 6) and the pointing device (figure 7).

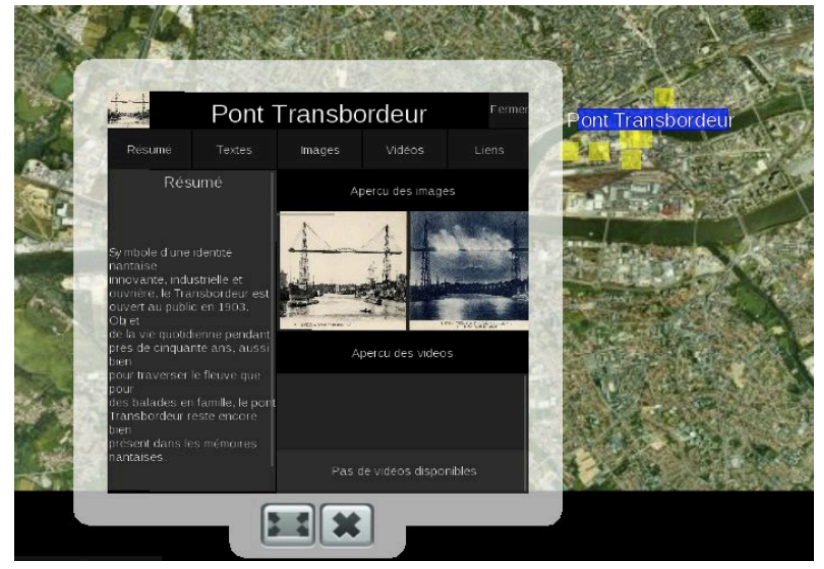

Figure 6. Information display example on the touch screen

There are two parts for using knowledge captured in the Nantes 1900 project:

- locally in the museum;

- $\quad$ access to content via the Internet.

The database can be filled by visitors then validated by experts. The name of the person who enters the data should also be recorded. The database must have full traceability of information that has been recorded. Indeed, one important aspect leads to the fact that the database conserves all versions of information; it is not as using a versioning system as sometimes elements which are not useful are destroyed; conversely, when dealing with history an hypothesis done nowadays can be cancelled by another hypothesis 
done few years ago (i.e. the current paradigm with Albert Einstein and its famous equilibrium equation) [14].

Localy, only data retrieval will be possible using the touch screen. People, whatever their knowledge about history, about the city of Nantes, whatever their status (student, teacher), their desire for details, can navigate through information and the $3 \mathrm{D}$ model, using an interface as intuitive as possible. Moreover, they can choose the level of details on the data displayed. Only resources (documents, news) validated and attached to a physical object (house, street, district) will be available from this interface.

In addition, a light pointer will be activated each time an object is selected on the virtual mock-up. Consequently, it will point the corresponding physical element directly on the model. The diameter of the beamer is automatically adjusted with the area defined by the visitor on the touch screen (figure 7).

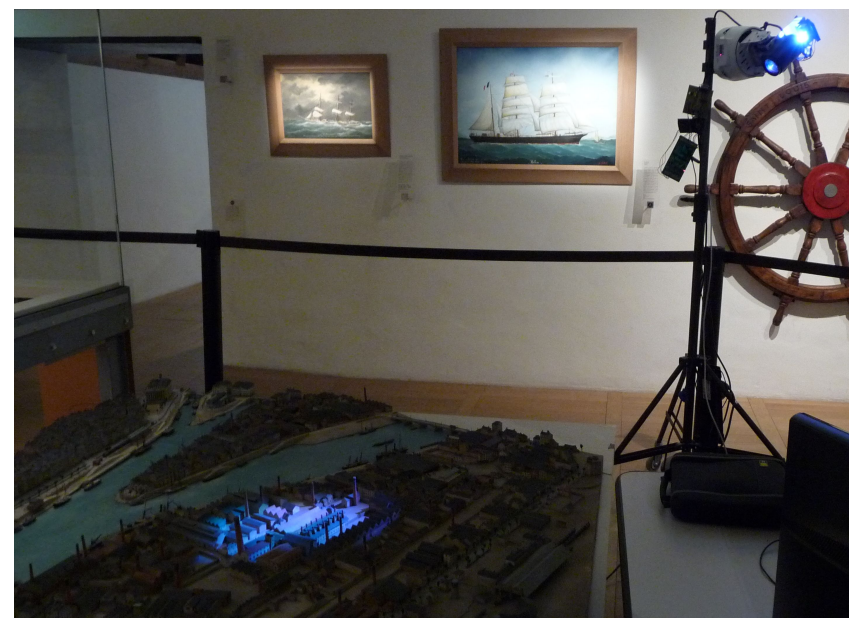

Figure 7. The pointer system lighting the Information display example on the touch screen

In addition, on web side, the database can be seen all over the world. Users, depending on their role, will have different ability to record their discoveries and even modify them. The database we have designed will be huge and will become a new work reference for researchers.

The process associated is:

1. a visitor comes inside the museum

2. he discovers knowledge associated on the touch screen

3. he remembers he has some information at home that are not in the museum application

4. he comes back home and goes to the website for filling his own information

5. experts will validate his information

6. and the knowledge created will instantly be accessible from the web site and in the museum application

The final deliverable in operation in Nantes History Museum "Château des Ducs de Bretagne" is planned for 2012.

\section{Conclusion AND PERSPECTIVES}

In this article, we present an experimentation we are doing in relationship with a French museum. The main goal is to create an innovative system valorie an old object: a physical mock-up representing Nantes harbor in 1900.

First, the mock-up had been digitized in 3 dimensions; which is a performance as digitizing large-scale object with high precision can be difficult. At the same time, a knowledge capitalization step allowed to create a database to model the social-economical activities of Nantes harbor: it is a corpus of documents, records, videos, images, etc. that helps to understand how the city of Nantes operated 100 years ago.

In order to present it to visitors, a new augmented reality system has been conceived. It is composed of a touch screen coupled to a light pointer that will allow visitors interact between the virtual and the physical model. Moreover, all the knowledge associated to the heritage object would be semantically indexed and will be displayed on the same touch screen. In addition, the database will be available on the Internet and everybody will be able to update it with new personal elements (images, comments, etc.). Regularly the web database will be synchronized to the device installed in the museum so visitors will always benefit of from updated data.

We may notice that one particularity of the project is that students do all work. Indeed, going from state B to state C (see figure 3 ) represents the valorization phase. One of the best ways to enhance our heritage for young generation is that young people themselves achieve the capitalization phase (state A to state B). Until now, approximately 90 students and 10 researchers-teachers have worked on the Nantes 1900 project. Moreover, we have to notice that multiple domains have been involved in this project, disciplines which frequently do not interact sufficiently.

To conclude, we can say that beyond this experience, this project shows the pioneer role in historical research and dissemination of scientific and technical knowledge. Now, using an old object becomes a pretext to develop contemporary and multidisciplinary project requiring high scientific background.

\section{REFERENCES}

[1] B. Guillet, L. Huron, J.-L. Kerouanton, "La maquette du Port de Nantes", French congress Des villes, des ports : la mer, les hommes (n 124; 1999; Nantes), Paris, 2001,

[2] D. Langweil, "Digitalization of Prague city, last step", 2008, http://www.praguemodels.cz/

[3] C. Chevrier, K. Jacquot, J.P. Perrin, 3D modelling of a town scale model, EuroMed Conference, Limassol, Cyprus, 10 p., Nov 2010.

[4] Frischer, B., "The Rome Reborn Project. How Technology is helping us to study history," OpEd, November 10, 2008. University of Virginia, 2008. [http://www.romereborn.virginia.edu/]

[5] Guidi, G., B. Frischer, et al., "Virtualizing Ancient Rome: 3D Acquisition and Modeling of a Large Plaster-of-Paris Model of Imperial Rome," Videometrics VIII, edited by J.-Angelo Beraldin, Sabry F. El-Hakim, Armin Gruen, James S. Walton, 18-20 January 2005, San Jose, California, USA, SPIE, vol. 5665, 119-133, 2005.

[6] P. Fleury, "La rome antique sur l'internet", Informatics and statistics review for human sciences, 1997.

[7] The Digital Michelangelo Project. [http://graphics.stanford.edu/projects/mich/]

[8] J.-P. Houdin, "3D Unveils the mystery of the great pyramid", http://www.3ds.com/introduction, web site seen the 3rd of March, 2007.

[9] G. Fiorenzoli, "La 3D révèle le fonctionnement de l'automobile de Léonard de Vinci", Revue La Forge, ${ }^{\circ}{ }^{18}$, pp.44-45, 2004 http://brunelleschi.imss.fi.it/automobile/index.html

[10] Z. Weiss, M. Pankowski), "Knowledge reengineering for reverse engineering purposes", CIRP Design Seminar Conference, Berlin, Germany, pp.421-430, 2007 - ISBN 978-3-540-69819-7

[11] W. Derigent, S. Remy, E. Chapotot, G. Ris, A. Bernard, "3D digitising strategy planning approach based on CAD model", Transactions of the ASME, Journal of Computing and Information Science In Engineering, vol. 7, n ${ }^{\circ}$, pp 10-19, 2007. 
[12] Livio De Luca, Philippe Véron, Michel Florenzano. Reverse engineering of architectural buildings based on a hybrid modeling approach. Computers \& Graphics. Volume 30, Issue 2, Pages 160176 Elsevier, april 2006.

[13] Laroche Florent , Bernard Alain, Cotte Michel, “Advanced Industrial Archaeology: A new reverse-engineering process for contextualizing and digitizing ancient technical objects" , Journal Virtual and Physical Prototyping, vol. 3, n ${ }^{\circ}$, Taylor \& Francis, p.105-122, 2008.

[14] Laroche Florent, Bernard Alain, Cotte Michel, "Between heritage and Industrial Engineering, a new life for old product: virtuality", conférence Virtual Concept, Cancun, Mexique, Revue Research in Interactive Design, Vol.2, Ed. Springer, novembre 2006, 7 p. - ISBN 2-287-48363-2 